\title{
Investigation of toxin gene diversity and antimicrobial resistance of Clostridium difficile strains
}

\author{
SHANSHAN ZHU, HUAPING ZHANG, XINSHENG ZHANG, CHAO WANG, GUANGMING FAN, \\ WEIFENG ZHANG, GANG SUN, HUIHONG CHEN, LIMING ZHANG and ZHAOYUN LI
}

Central Hospital of Taizhou City, Taizhou, Zhejiang 318000, P.R. China

Received May 16, 2014; Accepted June 26, 2014

DOI: 10.3892/br.2014.311

\begin{abstract}
The incidence of Clostridium difficile infection (CDI) has been previously reported in a number of studies. However, data collected from the Chinese population is limited. In the present study, the diversity of the toxin genes, $t c d A$ and $t c d B$, of 57 Clostridium difficile $(C$. difficile) isolates from a Chinese population were investigated by polymerase chain reaction (PCR) $\left(38 \mathrm{~A}^{+} \mathrm{B}^{+}, 14 \mathrm{~A}^{-} \mathrm{B}^{+}\right.$and $\left.5 \mathrm{~A}^{-} \mathrm{B}^{-}\right)$. Quantitative PCR was used to check the expression of these two genes and it was found that the genes were not expressed by all the strains. The absence of $t c d A$ or $t c d B$ expression in certain strains could be due to the lower expression of $t c d D$ and the higher expression of $t c d C$, which are positive and negative regulators for these two toxin genes, respectively. In addition, the antimicrobial susceptibilities of 57 isolates were investigated. Therefore, these data would aid in the future prevention of CDI outbreaks and improve the understanding of the infection.
\end{abstract}

\section{Introduction}

Clostridium difficile $(C$. difficile) has been associated with a wide range of diseases, including toxic megacolon, nosocomial diarrhea and pseudomembranous colitis $(1,2)$. Toxigenic and epidemic $C$. difficile is a well-established health threat in the nosocomial environment. Several studies have shown that $C$. difficile causes community-acquired infections and it has been isolated from various human, animal, food and environmental sources, often with similar genetic profiles $(3,4)$. The pathogenicity of $C$. difficile is associated with its ability to produce two toxins: Toxin A, an enterotoxin; and toxin B, a potent cytotoxin (5), which are responsible for the cellular damage linked to diseases. The $t c d A$ and $t c d B$ genes that encode toxins $\mathrm{A}$ and $\mathrm{B}$, respectively, are located in the pathogenicity

Correspondence to: Professor Zhaoyun Li, Central Hospital of Taizhou City, 999 Donghai Avenue, Taizhou, Zhejiang 318000, P.R. China

E-mail: 1zy8151@163.com

Key words: Clostridium difficile infection, antimicrobial susceptibilities, toxin genes, $t c d A, t c d B$ locus (PaLoc), along with the positive and negative regulator genes, $t c d D$ and $t c d C$, respectively (6). Several polymerase chain reaction (PCR) methods have been developed to detect the $t c d A$ and $t c d B$ genes and there have been certain studies of the toxin gene diversity, molecular epidemiology and antimicrobial resistance of $C$. difficile isolated from hospitals. However, thus far, limited data are available on the toxin gene diversity and antimicrobial susceptibilities of the bacterium isolated from $C$. difficile infection (CDI) patients in China. In the present study, $C$. difficile isolates were analyzed from patients in the Central Hospital of Taizhou City (Taizhou, China) for the presence of the $t c d D, t c d C, c d t A$ and $c d t B$ genes and the expression patterns were examined via quantitative PCR (qPCR). Additionally, the susceptibility of the $C$. difficile profiles to 12 antimicrobial agents, including nemonoxacin and tigecycline, were investigated.

\section{Materials and methods}

Identification of $C$. difficile isolates. The faecal samples were collected from various departments of the Taizhou Central Hospital. Isolation of $C$. difficile was performed on selective Columbia agar supplemented (bioMerieux Co., Ltd., Shanghai, China) with cycloserine-cefoxitin and amphotericin B (Bayer Co., Ltd., Shanghai, China) as described previously (7). Briefly, the plates were incubated in an anaerobic chamber at $37^{\circ} \mathrm{C}$ for $72 \mathrm{~h}$. The $C$. difficile isolates were identified by colony morphology, Gram staining, odor and green-yellow fluorescence under UV light (365 nm).

PCR assays. All the PCR reactions were performed with a positive and negative control using the primers (Table I) described by previous studies $(8,9)$. PCR was conducted with $2.5 \mathrm{pl}$ cDNA and $15 \mathrm{pmol}$ of each primer pair in a total volume of $50 \mathrm{p} 1$ with 1 unit of Taq DNA polymerase (Takara Bio, Inc., Shiga, Japan) in a standard reaction mixture. Amplification was achieved by denaturing at $95^{\circ} \mathrm{C}(1 \mathrm{~min})$, primer annealing at $52^{\circ} \mathrm{C}(1 \mathrm{~min})$ and extension at $72^{\circ} \mathrm{C}(1 \mathrm{~min})$, which were repeated for 30 cycles.

RNA extraction, cDNA synthesis and qPCR assays. cDNA synthesis was performed as described previously by Frias-Lopez et al (9). RNA was extracted from cultured bacterial cells using AllPrep DNA/RNA mini kit (Qiagen, 
Hilden, Germany) following the manufacturer's instructions and 2-3 $\mu \mathrm{g}$ RNA was expected to be obtained. To eliminate the potential contamination by DNA, the TURBO DNA-free ${ }^{\mathrm{TM}}$ kit was utilized (Applied Biosystems, Foster City, CA, USA) following the manufacturer's instructions. Subsequently, RNA was reverse transcribed into first strand cDNA using the SuperScript III First-Stand Synthesis SuperMix kit (Invitrogen Life Technologies, Carlsbad, CA, USA) and random hexamer priming. qPCR was performed using the KAPA SYBR FAST qPCR kit (Kapa Biosystems, Woburn, MA, USA) following the manufacturer's instructions: Denaturing at $95^{\circ} \mathrm{C}(1 \mathrm{~min})$, primer annealing at $52^{\circ} \mathrm{C}(1 \mathrm{~min})$ and extension at $72^{\circ} \mathrm{C}(1 \mathrm{~min})$, repeated for 30 cycles. The increase in fluorescence was measured in real-time during the extension step. The primers used are listed in (Table I). The $\Delta \mathrm{Ct}$ values for each sample between the toxin genes and 16S rRNA were calculated and are listed in Table II. The relative expression levels of $t c d C$ and $t c d D$ were calculated based on the $\Delta \mathrm{Ct}$ values between the two genes and 16S rRNA.

Antimicrobial susceptibility testing. The antimicrobial susceptibility tests were performed with $57 \mathrm{C}$. difficile isolates as described previously (10). Briefly, an inoculum of $10^{5} \mathrm{CFU}$ bacteria was applied to each plate with a glass replicator on supplemented Brucella blood agar (11). The plates were incubated in an anaerobic chamber for $48 \mathrm{~h}$ at $37^{\circ} \mathrm{C}$. The minimal inhibitory concentration (MIC) was defined as the lowest concentration of each antimicrobial agent that inhibited the growth of the tested isolate. The antimicrobial agents (Sigma-Aldrich, St. Louis, MO, USA) used are listed in Table III.

\section{Results}

Analysis of the toxin genes, tcdA and tcdB. C. difficile were isolated from various departments of the hospital: 20 from the Department of Neurosurgery, 7 from the Intensive Care Unit, 10 from the Department of Infectious Diseases, 10 from the Department of Hematology and 10 from the Department of Radiation Oncology (Table II). The PCR assay was used to differentiate toxin A-negative and B-positive (toxin $\mathrm{A}^{-}$, toxin $\mathrm{B}^{+}$) strains from the toxin-positive (toxin $\mathrm{A}^{+}$, toxin $\mathrm{B}^{+}$) strains and the toxin-negative (toxin $\mathrm{A}^{-}$, toxin $\mathrm{B}^{-}$) strains. The primers used are listed in Table I. As shown in Table II, 38 and 14 isolates of the $\mathrm{A}^{+} \mathrm{B}^{+}$and $\mathrm{A}^{-} \mathrm{B}^{+}$strains were identified, respectively, which were the toxigenic strains. The recovery rates of the toxigenic strains were $85-100 \%$ according to the hospital studied. By contrast, 5 isolates were $\mathrm{A}^{-} \mathrm{B}^{-}$. To investigate the expression levels of $t c d A$ and $t c d B$ genes, qPCR was performed. The $\mathrm{Ct}$ values were summarized in Table II. Of the total $38 t c d A$ PCR-positive isolates, 36 could be detected for the expression of this gene and the expression level varied slightly between the 36 transcripts. Of the total $52 t c d B$ PCR-positive isolates, the expression of this gene could be identified in 50 qPCR transcripts and they showed slight variations in the expression level as well. No transcription could be detected in the $\mathrm{A}^{-} \mathrm{B}^{-}$isolates.

Detection of the tcdC and tcdD genes. Based on these results, the transcription of $t c d A$ could not be detected in isolates 37
Table I. Primers used in the present study.

\begin{tabular}{ll}
\hline Primers & \multicolumn{1}{c}{ Oligonucleotide sequence $\left(5^{\prime} \rightarrow 3^{\prime}\right)$} \\
\hline$t c d A-P C R-F$ & CCCAATAGAAGATTCAATATTAAGCTT \\
$t c d A$-PCR-R & GGAAGAAAAGAACT \\
& TCTGGCTCACTCAGGT \\
$t c d B$-PCR-F & GGTGGAGCTGCTTCATTGGAGAG \\
$t c d B$-PCR-R & GTGTAACCTACTTTCATAACACCA \\
$t c d A$-qPCR-F & TCTACCACTGAAGCATTAC \\
$t c d A-q P C R-R$ & TAGGTACTGTAGGTTTATTG \\
$t c d B$-qPCR-F & ATATCAGAGACTGATGAG \\
$t c d B$-qPCR-R & TAGCATATTCAGAGAATATTG \\
$t c d C$-qPCR-F & TCTCTACAGCTATCCCTGGT \\
$t c d C$-qPCR-R & AAAAATGAGGGTAACGAATTT \\
$t c d D$-qPCR-F & CTCAGTAGATGATTTGCAAGAA \\
$t c d D$-qPCR-R & TTTTAAATGCTCTATTTTTAGCC
\end{tabular}

qPCR, quantitative polymerase chain reaction; F, forward; $R$, reverse.

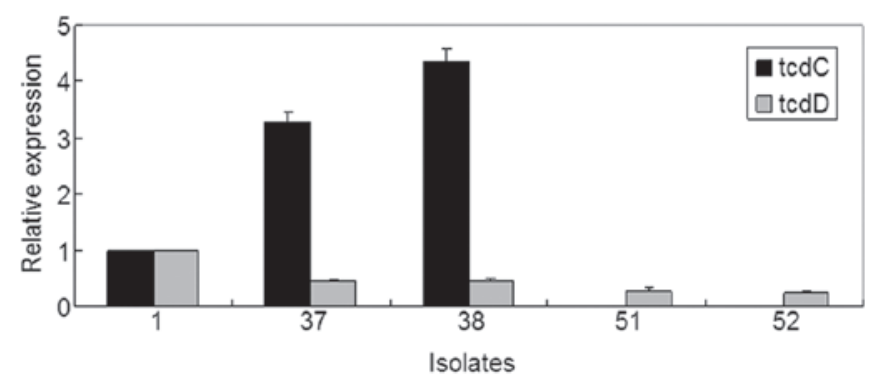

Figure 1. Quantitative polymerase chain reaction detection of the $t c d C$ and tcdD genes in the Clostridium difficile isolates.

and 38, and the transcription of $t c d B$ could not be detected in isolates 51 and 52. As mentioned above, TcdD and TcdC have been indicated as the positive and negative regulators of toxin A and B expression, respectively (6). In order to investigate why the $t c d A$ or $t c d B$ genes are not expressed in isolates $37,38,51$ and $52, \mathrm{qPCR}$ was performed to detect the expression of $t c d C$ and $t c d D$. Isolate 1 , which showed a high expression of the $t c d A$ and $t c d B$ genes, was used as a positive control. The results (Fig. 1) showed that the mRNA level of $t c d D$ was lower in isolates 37 and 38 compared to isolate 1 , and by contrast, the $t c d C$ mRNA level was relatively higher. Furthermore, the mRNA level of $t c d D$ was notably lower in isolates 51 and 52, whereas no transcription of $t c d C$ was detected in these two isolates.

Antimicrobial susceptibilities. The MIC ranges, MIC50s, MIC90s and the percentages of the susceptibility of 57 C. difficile isolates to 12 antimicrobial agents are summarized in Table III. All the isolates were susceptible to vancomycin (MIC, $\leq 2 \mu \mathrm{g} / \mathrm{ml}$ ). Susceptibility to piperacillin, ampicillin-sulbactam, imipenem, meropenem, metronidazole and tigecycline was shown in $>80 \%$ isolates. The resistance rates to cefotetan, moxifloxacin and ertapenem were $>70 \%$. However, no isolates 
Table II. PCR and qPCR detection of the $t c d A$ and $t c d B$ genes.

\begin{tabular}{|c|c|c|c|c|c|c|c|c|c|}
\hline \multirow[b]{3}{*}{ Isolates } & \multirow[b]{3}{*}{ Unit } & & & \multicolumn{6}{|c|}{ qPCR } \\
\hline & & \multicolumn{2}{|c|}{ PCR } & \multicolumn{3}{|c|}{$t c d A$} & \multicolumn{3}{|c|}{$t c d B$} \\
\hline & & $t c d A$ & $t c d B$ & $\Delta \mathrm{Ct} 1$ & $\Delta \mathrm{Ct} 2$ & $\Delta \mathrm{Ct} 3$ & $\Delta \mathrm{Ct} 1$ & $\Delta \mathrm{Ct} 2$ & $\Delta \mathrm{Ct} 3$ \\
\hline 1 & $\mathrm{DN}$ & + & + & 2.90 & 2.75 & 2.66 & 5.76 & 5.33 & 5.53 \\
\hline 2 & DN & + & + & 2.11 & 2.23 & 2.83 & 4.32 & 4.36 & 4.57 \\
\hline 3 & $\mathrm{DN}$ & + & + & 1.56 & 1.58 & 1.63 & 5.23 & 5.55 & 5.34 \\
\hline 4 & $\mathrm{DN}$ & + & + & 2.52 & 2.67 & 2.54 & 2.98 & 2.75 & 2.54 \\
\hline 5 & $\mathrm{DN}$ & + & + & 2.70 & 2.65 & 2.63 & 4.87 & 4.54 & 4.34 \\
\hline 6 & $\mathrm{DN}$ & + & + & 2.55 & 2.44 & 2.48 & 3.21 & 3.45 & 3.65 \\
\hline 7 & $\mathrm{DN}$ & + & + & 2.33 & 2.35 & 2.37 & 3.35 & 3.45 & 3.37 \\
\hline 8 & $\mathrm{DN}$ & + & + & 3.64 & 3.70 & 3.72 & 3.34 & 3.75 & 3.44 \\
\hline 9 & DN & + & + & 2.31 & 2.11 & 2.34 & 5.43 & 5.46 & 5.67 \\
\hline 10 & $\mathrm{DN}$ & + & + & 1.06 & 1.05 & 0.91 & 4.83 & 4.92 & 4.44 \\
\hline 11 & $\mathrm{DN}$ & + & + & 1.01 & 1.09 & 1.13 & 5.43 & 5.55 & 5.57 \\
\hline 12 & ICU & + & + & 0.05 & 0.03 & 0.02 & 6.71 & 6.32 & 6.43 \\
\hline 13 & ICU & + & + & 2.13 & 2.14 & 2.23 & 5.31 & 5.21 & 5.55 \\
\hline 14 & $\mathrm{DN}$ & + & + & 2.37 & 2.39 & 2.30 & 5.73 & 5.77 & 5.78 \\
\hline 15 & $\mathrm{DN}$ & + & + & 3.68 & 3.72 & 3.71 & 4.32 & 4.33 & 4.37 \\
\hline 16 & $\mathrm{DN}$ & + & + & 2.97 & 2.95 & 2.92 & 3.21 & 3.22 & 3.34 \\
\hline 17 & $\mathrm{DN}$ & + & + & 3.21 & 3.24 & 3.26 & 2.34 & 2.37 & 2.39 \\
\hline 18 & $\mathrm{DN}$ & + & + & 1.09 & 1.11 & 1.13 & 1.29 & 1.27 & 1.25 \\
\hline 19 & $\mathrm{DN}$ & + & + & 1.21 & 1.22 & 1.19 & 2.32 & 2.35 & 2.42 \\
\hline 20 & $\mathrm{DN}$ & + & + & 1.24 & 1.29 & 1.27 & 2.55 & 2.57 & 2.60 \\
\hline 21 & DD & + & + & 0.36 & 0.34 & 0.39 & 3.21 & 2.98 & 3.02 \\
\hline 22 & DD & + & + & 1.02 & 1.03 & 1.05 & 4.56 & 4.57 & 4.58 \\
\hline 23 & DD & + & + & 2.01 & 2.07 & 1.98 & 2.22 & 2.25 & 2.29 \\
\hline 24 & DD & + & + & 3.03 & 3.05 & 3.07 & 4.59 & 4.54 & 4.56 \\
\hline 25 & DD & + & + & 4.51 & 4.55 & 4.52 & 3.37 & 3.41 & 3.21 \\
\hline 26 & DD & + & + & 2.72 & 2.71 & 2.69 & 2.21 & 2.29 & 2.31 \\
\hline 27 & DD & + & + & 1.67 & 1.72 & 1.69 & 3.98 & 3.96 & 3.92 \\
\hline 28 & DD & + & + & 1.79 & 1.78 & 1.78 & 6.53 & 6.52 & 6.32 \\
\hline 29 & DD & + & + & 0.77 & 0.78 & 0.80 & 5.90 & 5.78 & 5.32 \\
\hline 30 & DD & + & + & 0.34 & 0.35 & 0.36 & 4.90 & 4.93 & 4.53 \\
\hline 31 & $\mathrm{DH}$ & + & + & 0.56 & 0.57 & 0.59 & 3.98 & 3.77 & 3.63 \\
\hline 32 & $\mathrm{DH}$ & + & + & 2.31 & 2.34 & 2.35 & 3.29 & 3.27 & 3.25 \\
\hline 33 & $\mathrm{DH}$ & + & + & 3.41 & 3.42 & 3.42 & 4.53 & 4.52 & 4.50 \\
\hline 34 & $\mathrm{DH}$ & + & + & 2.79 & 2.78 & 2.77 & 2.98 & 2.97 & 2.93 \\
\hline 35 & $\mathrm{DH}$ & + & + & 1.56 & 1.58 & 1.54 & 1.95 & 1.92 & 1.93 \\
\hline 36 & $\mathrm{DH}$ & + & + & 1.96 & 1.94 & 1.93 & 4.78 & 4.79 & 4.70 \\
\hline 37 & $\mathrm{DH}$ & + & + & NA & NA & NA & 4.56 & 4.67 & 4.98 \\
\hline 38 & $\mathrm{DH}$ & + & + & NA & NA & NA & 3.32 & 3.45 & 3.56 \\
\hline 39 & DPE & - & + & NA & NA & NA & 5.97 & 5.67 & 5.88 \\
\hline 40 & DPE & - & + & NA & NA & NA & 2.60 & 2.70 & 2.66 \\
\hline 41 & ICU & - & + & NA & NA & NA & 3.01 & 3.04 & 2.34 \\
\hline 42 & ICU & - & + & NA & NA & NA & 3.77 & 3.58 & 3.60 \\
\hline 43 & ICU & - & + & NA & NA & NA & 3.62 & 3.64 & 3.65 \\
\hline 44 & $\mathrm{DH}$ & - & + & NA & NA & NA & 4.21 & 4.22 & 4.23 \\
\hline 45 & $\mathrm{DH}$ & - & + & NA & NA & NA & 5.32 & 5.33 & 5.34 \\
\hline 46 & DRO & - & + & NA & NA & NA & 5.29 & 5.29 & 5.27 \\
\hline
\end{tabular}

qPCR, quantitative polymerase chain reaction; DN, Department of Neurosurgery; ICU, Intensive Care Unit; DD, Department of Infectious Diseases; DH, Department of Hematology; NA, not applicable; DPE, Department of Physical Examination; DRO, Department of Radiation Oncology. 
Table II. Continued.

\begin{tabular}{|c|c|c|c|c|c|c|c|c|c|}
\hline \multirow[b]{3}{*}{ Isolates } & \multirow[b]{3}{*}{ Unit } & & & \multicolumn{6}{|c|}{ qPCR } \\
\hline & & \multicolumn{2}{|c|}{ PCR } & \multicolumn{3}{|c|}{$t c d A$} & \multicolumn{3}{|c|}{$t c d B$} \\
\hline & & $t c d A$ & $t c d B$ & $\Delta \mathrm{Ct} 1$ & $\Delta \mathrm{Ct} 2$ & $\Delta \mathrm{Ct} 3$ & $\Delta \mathrm{Ct} 1$ & $\Delta \mathrm{Ct} 2$ & $\Delta \mathrm{Ct} 3$ \\
\hline 47 & DRO & - & + & NA & NA & NA & 3.55 & 3.57 & 3.59 \\
\hline 48 & DRO & - & + & NA & NA & NA & 3.11 & 3.12 & 3.17 \\
\hline 49 & DRO & - & + & NA & NA & NA & 4.19 & 4.17 & 4.16 \\
\hline 50 & DRO & - & + & NA & NA & NA & 2.48 & 2.47 & 2.39 \\
\hline 51 & DRO & - & + & NA & NA & NA & NA & NA & NA \\
\hline 52 & DRO & - & + & NA & NA & NA & NA & NA & NA \\
\hline 53 & $\mathrm{ICU}$ & - & - & NA & NA & NA & NA & NA & NA \\
\hline 54 & ICU & - & - & NA & NA & NA & NA & NA & NA \\
\hline 55 & DRO & - & - & NA & NA & NA & NA & NA & NA \\
\hline 56 & DRO & - & - & NA & NA & NA & NA & NA & NA \\
\hline 57 & DRO & - & - & NA & NA & NA & NA & NA & NA \\
\hline
\end{tabular}

qPCR, quantitative polymerase chain reaction; DN, Department of Neurosurgery; ICU, Intensive Care Unit; DD, Department of Infectious Diseases; DH, Department of Hematology; NA, not applicable; DPE, Department of Physical Examination; DRO, Department of Radiation Oncology.

Table III. Minimal inhibitory concentrations (MICs) of 12 antimicrobial agents for the 57 Clostridium difficile isolates.

\begin{tabular}{lrrrr}
\hline & \multicolumn{3}{c}{ MIC (mg/l) } \\
\cline { 2 - 5 } Antimicrobial agent & MIC50 & MIC90 & Range & Resistant, \% \\
\hline Vancomycin & 0.40 & 1.50 & $0.28-2.00$ & 0.00 \\
Piperacillin & 4.20 & 26.00 & $0.92-33.00$ & 7.02 \\
Ampicillin-sulbactam & 1.65 & 6 & $0.24-10.00$ & $1.9-32.00$ \\
Imipenem & 10.00 & 18.20 & $0.95-15.00$ & 8.77 \\
Meropenem & 3.20 & 10.20 & $0.125-5.50$ & 17.54 \\
Metronidazole & 0.80 & 2.56 & $0.03-0.36$ & $1.8-185.00$ \\
Tigecycline & 0.08 & 0.10 & $0.9-175.00$ & 21.05 \\
Cefotetan & 35.00 & 168.00 & $0.03-67.00$ & 63.15 \\
Moxifloxacin & 2.80 & 37.00 & $45-156.00$ & 87.7 \\
Ertapenem & 4.00 & 39.00 & $4-333.00$ & 100.00 \\
Cefoxitin & 101.00 & 145.00 & 267.00 &
\end{tabular}

were susceptible to cefoxitin or clindamycin. Tigecycline demonstrated the lowest MIC50 (0.08 mg/l) and inhibited all the strains at $0.36 \mathrm{mg} / \mathrm{l}$, whereas cefoxitin showed the highest MIC50 (101 mg/l). Tigecycline was also the most active with regards to MIC90 $(0.1 \mathrm{mg} / \mathrm{l})$, whereas clindamycin had the highest MIC90 (267 mg/l).

\section{Discussion}

The toxin gene diversity has been investigated in numerous studies by PCR (10). For example, the multiplex PCR method by Persson et al (14) allowed the simultaneous identification of the $t c d A, t c d B, c d t A$ and $c d t B$ toxin genes. In addition, a multiplex qPCR method for the detection of toxigenic $C$. difficile from stools and the presumptive identification of the NAP-1 strain was developed by Jayaratne et al (15). In the present study, PCR and qPCR were carried out to identify the $t c d A$ and $t c d B$ toxin genes in 57 isolated samples from the Central Hospital of Taizhou City, and the study was a systematic survey of the types of the $C$. difficile toxin genes in China. The results showed that of the 57 isolates, $38(66.67 \%)$ were $\mathrm{A}^{+} \mathrm{B}^{+}$, which plays a major role in CDI. A total of 14 (24.56\%) isolates were $\mathrm{A}^{-} \mathrm{B}^{+}$strains, which have been reported to be significantly increased during recent years (16). In studies from various global locations, different proportions of the $\mathrm{A}^{-} \mathrm{B}^{+}$strains have been reported $(17,18)$. In the present study, based on the PCR results, the $\mathrm{A}^{-} \mathrm{B}^{-}$strain accounted for only 5 (8.77\%) of the isolates. However, according to the qPCR results, not all the 
$\mathrm{A}^{+}$or $\mathrm{B}^{+}$isolates showed detectable expression of these genes. This can be explained by the inhibition of $t c d A$ or $t c d B$ transcription by regulators in certain strains. By contrast, it has also been reported that there are certain activators, including $\sigma$ factors and the positive regulator $\mathrm{TcdD}$, which are necessary for the expression of TcdA and TcdB (19). Therefore, the absence of these types of activators may be another reason why these two genes are not expressed. However, this requires further investigation.

Certain studies (20) have focused on the regulation of the $t c d A$ and $t c d B$ toxin genes. Earlier studies (21) indicated that $\mathrm{TcdC}$ has a negative influence on the transcription of the other genes in PaLoc, consisting of the $t c d A-E$ genes, and TcdD has a positive regulatory function on the transcription of the $t c d D$, $t c d B, t c d E$ and $t c d A$ genes. In the present study, the mRNA levels of the $t c d C$ and $t c d D$ genes were detected in isolates 1,37, 38,51 and 52 to identify why $t c d A$ or $t c d B$ are not transcribed. Consistent with previous studies (22), the mRNA level of $t c d C$ was significantly higher in isolates 37 and 38, in which the toxin $t c d A$ was not detectable, indicating that the transcription of $t c d A$ could be inhibited by TcdC. Notably, no transcription of $t c d C$ could be detected in isolates 51 and 52, possibly due to the absence of this gene in the strains. Spigaglia et al (23) have previously reported the deletion of $t c d C$ in $C$. difficile clinical isolates. By contrast, another reason why $t c d A$ is not expressed in isolates $37,38,51$ and 52 could be due to the low expression of $t c d D$.

The susceptibility of the $57 \mathrm{C}$. difficile isolates to 12 antimicrobial agents was also investigated. All the isolates of C. difficile showed susceptibility to vancomycin, which is consistent with the fact that it is an effective agent against $C$. difficile infection (24). In addition, the $C$. difficile isolates in the present study were universally susceptible to piperacillin, ampicillin-sulbactam, imipenem and meropenem. Based on the study by Settle et al (25), it has been proved that piperacillin, regarding its broad-spectrum activity particularly against anaerobes, was relatively more likely to induce $C$. difficile colonization or diarrhea. Thus, it is not widely used in hospitals. Notably, $90 \%$ of the isolates in the present study were susceptible to imipenem, which varies from the results of previous studies $(12,26)$. In an investigation of the inhibitory activity of antimicrobial agents against clinical isolates of $C$. difficile by Cheng et al (26), found resistance to imipenem in the majority of tested strains. Ampicillin-sulbactam has been reported to be active against $C$. difficile in numerous studies $(27,28)$. Similar to the results in the present study, Lin et al (28) and Hecht et al (29) also demonstrated that meropenem had low MIC90 values (4 and $2 \mu \mathrm{g} / \mathrm{ml}$, respectively). Tigecycline had the lowest MIC90 value for $C$. difficile isolates and was followed by vancomycin and metronidazole (all, $>3 \mathrm{mg} / \mathrm{l}$ ), which is similar to previous studies $(30,31)$. Tigecycline has been proved to not induce proliferation or cytotoxin production by epidemic $C$. difficile strains, and patients with severe refractory CDI were successfully treated with tigecycline $(32,33)$. Clindamycin showed the highest MIC90 of all the antimicrobial agents tested, consistent with the study by Lin et al (28) and as previously reported by Critchley (34), the use of clindamycin was independently associated with the infection of $C$. difficile.

In conclusion, the present study identified the presence of the $t c d A$ and $t c d B$ toxin genes in the isolates of 57 C. difficile isolates from Chinese patients, using PCR and qPCR. Similar to previous studies, the $\mathrm{A}^{+} \mathrm{B}^{+}$was the dominant ribotype. Certain isolates were shown to be lacking $t c d A$ or the $t c d B$ gene expression, possibly due to the absent or higher expression of $t c d C$ and lower expression of $t c d D$. The susceptibility of the genes to 12 agents was also investigated. The isolates showed similar susceptibility to specific agents, as reported previously, such as ampicillin-sulbactam. However, certain agents appeared to be more active against the isolates in the present study compared to in previous studies, such as imipenem. These data provide novel information on the characteristics of $C$. difficile isolated from Chinese patients and would aid in the future prevention of outbreaks.

\section{Acknowledgements}

The present study was supported by the Science and Technology Plan of Medicine and Health of Zhejiang (grant no. 2010KYA186). The authors are grateful to Dr Lin Liu, Mrs. Beijia Zheng, Mrs. Jinfeng Li and Mr. Xueyong Li for providing the clinical samples in the study and to Caixia Zhu for critical reading of the manuscript.

\section{References}

1. Bartlett JG, Chang TW, Gurwith M, et al: Antibiotic-associated pseudomembranous colitis due to toxin-producing clostridia. N Engl J Med 298: 531-534, 1978.

2. McFarland LV, Surawicz CM and Stamm WE: Risk factors for Clostridium difficile carriage and $C$. difficile-associated diarrhea in a cohort of hospitalized patients. J Infect Dis 162: 678-684, 1990.

3. Freeman J, Bauer MP, Baines SD, et al: The changing epidemiology of Clostridium difficile infections. Clin Microbiol Rev 23: 529-549, 2010.

4. Arroyo LG1, Kruth SA, Willey BM, Staempfli HR, Low DE and Weese JS: PCR ribotyping of Clostridium difficile isolates originating from human and animal sources. J Med Microbiol 54: 163-166, 2005.

5. Hatheway CL: Toxigenic clostridia. Clin Microbiol Rev 3: 66-98, 1990.

6. Spigaglia P and Mastrantonio P: Comparative analysis of Clostridium difficile clinical isolates belonging to different genetic lineages and time periods. J Med Microbiol 53: 1129-1136, 2004.

7. Martirosian G: Recovery of Clostridium difficile from hospital environments. J Clin Microbiol 44: 1202-1203, 2006.

8. Samie A, Obi CL, Franasiak J, et al: PCR detection of Clostridium difficile triose phosphate isomerase (tpi), toxin A (tcd A), toxin B (tcdB), binary toxin (cdtA, cdtB), and tcdC genes in Vhembe District, South Africa. Am J Trop Med Hyg 78: 577-585, 2008.

9. Frias-Lopez J, Shi Y, Tyson GW, et al: Microbial community gene expression in ocean surface waters. Proc Natl Acad Sci USA 105: 3805-3810, 2008.

10. Zhu S, Zhang L, Zhang C, et al: Comparison of polymerase chain reaction ribotyping, toxinotyping and nutritional aspects of toxin production of Clostridium difficile strains. Biomed Rep 2: 477-480, 2014.

11. Bélanger SD, Boissinot M, Clairoux N, et al: Rapid detection of Clostridium difficile in feces by real-time PCR. J Clin Microbiol 41: 730-734, 2003.

12. John R and Brazier JS: Antimicrobial susceptibility of polymerase chain reaction ribotypes of Clostridium difficile commonly isolated from symptomatic hospital patients in the UK. J Hosp Infect 61: 11-14, 2005.

13. Clinical and Laboratory Standards Institute (CLSI): Methods for antimicrobial susceptibility testing of anaerobic bacteria, approved standard M11-A7. 7th edition. CLSI, Wayne, PA, pp 309-315, 2007.

14. Persson S, Jensen JN and Olsen KE: Multiplex PCR method for detection of Clostridium difficile tcd A, tcdB, cdtA, and $\operatorname{cdtB}$ and internal in-frame deletion of tcdC. J Clin Microbiol 49: 4299-4300, 2011. 
15. Jayaratne PA, Monkman L, Broukhanski G, et al: Real-time polymerase chain reaction method for detection of toxigenic Clostridium difficile from stools and presumptive identification of NAP1 clone. Diagn Microbiol Infect Dis 75: 121-123, 2013.

16. Du P, Cao B, Wang J, et al: Sequence variation in tcdA and tcdB of Clostridium difficile: ST37 with truncated tcdA is a potential epidemic strain in China. J Clin Microbiol June 23, 2014 (Epub ahead of print).

17. Geric B, Rupnik M, Gerding DN, et al: Distribution of Clostridium difficile variant toxinotypes and strains with binary toxin genes among clinical isolates in an American hospital. J Med Microbiol 53: 887-894, 2004.

18. Kim H, Riley TV, Kim M, et al: Increasing prevalence of toxin A-negative, toxin B-positive isolates of Clostridium difficile in Korea: impact on laboratory diagnosis. J Clin Microbiol 46: 1116-1117, 2008

19. Saujet L, Monot M, Dupuy, B, et al: The key sigma factor of transition phase, SigH, controls sporulation, metabolism, and virulence factor expression in Clostridium difficile. J Bacteriol 193: 3186-3196, 2011

20. Gerding DN, Johnson S, Rupnik M and Aktories K: Clostridium difficile binary toxin CDT: mechanism, epidemiology, and potential clinical importance. Gut Microbes 5: 15-27, 2014.

21. Goldenberg SD and French GL: Lack of association of $t c d C$ type and binary toxin status with disease severity and outcome in toxigenic Clostridium difficile. J Infect 62: 355-362, 2011.

22. Antunes A and Dupuy B: Molecular methods to study transcriptional regulation of Clostridium difficile toxin genes. Methods Mol Biol646: 93-115, 2010.

23. Spigaglia P, Barbanti F, Dionisi AM and Mastrantonio P: Clostridium difficile isolates resistant to fluoroquinolones in Italy: emergence of PCR ribotype 018. J Clin Microbiol 48: 2892-2896, 2010.

24. Gerding DN, Muto CA and Owens RC Jr: Treatment of Clostridium difficile infection. Clin Infect Dis 46 (Suppl 1): S32-S42, 2008

25. Settle CD, Wilcox MH, Fawley WN, et al: Prospective study of the risk of Clostridium difficile diarrhoea in elderly patients following treatment with cefotaxime or piperacillin-tazobactam. Aliment Pharmacol Ther 12: 1217-1223, 1998
26. Cheng SH, Chu FY, Lo SH and Lu JJ: Antimicrobial susceptibility of Clostridium difficile by $\mathrm{E}$ test. J Microbiol Immunol Infect 32: 116-120, 1999.

27. Ednie LM, Jacobs MR and Appelbaum PC: Activities of gatifloxacin compared to those of seven other agents against anaerobic organisms. Antimicrob Agents Chemother 42: 2459-2462, 1998.

28. Lin YC, Huang YT, Tsai PJ, et al: Antimicrobial susceptibilities and molecular epidemiology of clinical isolates of Clostridium difficile in Taiwan. Antimicrob Agents Chemother 55: 1701-1705, 2011.

29. Hecht DW, Galang MA, Sambol SP, et al: In vitro activities of 15 antimicrobial agents against 110 toxigenic Clostridium difficile clinical isolates collected from 1983 to 2004. Antimicrob Agents Chemother 51: 2716-2719, 2007.

30. Larson KC, Belliveau PP and Spooner LM: Tigecycline for the treatment of severe Clostridium difficile infection. Ann Pharmacother 45: 1005-1010, 2011.

31. Wilcox MH: Evidence for low risk of Clostridium difficile infection associated with tigecycline. Clin Microbiol Infect 13: 949-952, 2007.

32. Baines SD, Saxton K, Freeman J, et al: Tigecycline does not induce proliferation or cytotoxin production by epidemic Clostridium difficile strains in a human gut model. J Antimicrob Chemother 58: 1062-1065, 2006.

33. Herpers BL, Vlaminckx B, Burkhardt $\mathrm{O}$, et al: Intravenous tigecycline as adjunctive or alternative therapy for severe refractory Clostridium difficile infection. Clin Infect Dis 48: 1732-1735, 2009.

34. Critchley IA, Green LS, Young CL, et al: Spectrum of activity and mode of action of REP3123, a new antibiotic to treat Clostridium difficile infections. J Antimicrob Chemother 63:954-963, 2009. 